\title{
Design of Interactive Teaching System for Color Design Course
}

\author{
https://doi.org/10.3991/ijet.v11i11.6244 \\ Fang Li \\ ZhouKou Normal University Academy of Fine Arts, Henan, China
}

\begin{abstract}
To make it convenient for users of the standard color library to find the most similar color, the measurement method of color similarity is studied, and a different color model is built and an accurate color similarity judgment method is found. Regarding to the status of the color design course in secondary vocational schools, the significance of the development of this aid system for color design course is well explained in this paper, and finally the harmony among the three factors is realized: the establishment of the color emotion index, the style of the color language, the color scheme of the three-dimensional semantic space.
\end{abstract}

Index Terms-interactive teaching system, color design course, color collocation

\section{INTRODUCTION}

Modern information technology is integrating with the whole process of education teaching, It gradually changes the process and pattern of original education teaching[1]. After a long developing history of artistic color, handicraft color and engineering color, Color Science now has evolved into the age of CACD (Computer Aided Color Design)[2-4]. Because of long time neglect of products' color design in Industrial Design field, the relevant researchers, scientific and technical references and research results of CACD are very limited compared with other Industrial Design directions of Computer Aided Form Design and Computer Aided Ergonomic Design[5-6].

To facilitate the users finding the most similar color in standard color database, the measurement of color similarity was studied and the methods of judging color similarity in different color models and precision were constructed[7]. The relationship between color harmony and color attributes was studied and the methods of color harmony in single attribute, double attributes and triple attributes were built. Color harmony can be gotten through hue, brightness, Chroma, tone and color solid. Single attribute color harmony includes hue harmony, brightness harmony and Chroma harmony. Double attributes harmony was realized by color tone design through synthesizing brightness with Chroma.

Wang's paper [2] researched teaching present situation of vocational school color design course and analyze problems, expounds the significance of color design teaching assistant system development background and development. According to the management information system demand analysis research method has carried on the demand analysis, function characteristics combined with the development of software for planning the teaching assistant system to achieve the function of. The outline design, and draw out the system structure chart of the teaching assistant system. In the implement phase system, the application of flash the technology is introduced, the module introduces the implementation process of the interactive function. Technical aspects of the main features of FLASH are introduced methods and principles of interaction design, the method call external files in FLASH.

\section{METHOD AND ALGORITHM}

"Color is the most expressive art language." In web design, if you are good at capturing the emotions of colors, it can often have special visual effects and emotional reaction. Designers in the web design should be good at capturing the emotional factors in colors. Figure 1 shows the OrCAD capture chart. Particularly, attention should be paid to the following aspects:

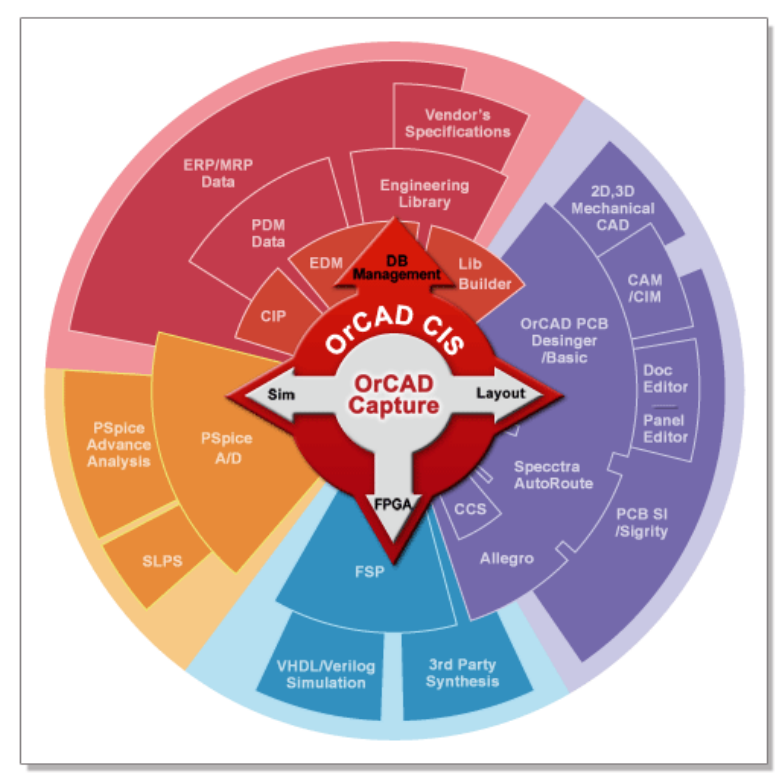

Figure 1. The OrCAD capture chart

Understand the information and brands conveyed by the website. To know the purpose of a brand and make a reasonable choice can strengthen the color collocation of corporate information. Different websites have different styles and personalized theme colors. Each color will lead to different emotions due to subtle changes of saturation and transparency. For a web designer, it is very important to do an aimed use of colors. There should be a big difference in web colors for different contents, so we should use the color language to reflect the characteristics and personality of a website to fully convey the emotional connotation and embody the theme.

$S_{H M}$ solution vectors are randomly generated accord- 
ing to the variable range for each variable. Namely,

$$
H M V=\left[\begin{array}{c|c}
\boldsymbol{x}^{1} & f\left(\boldsymbol{x}^{1}\right) \\
\boldsymbol{x}^{2} & f\left(\boldsymbol{x}^{2}\right) \\
\mathrm{M} & \mathrm{M} \\
\boldsymbol{x}^{S_{H M}} & f\left(\boldsymbol{x}^{S_{H M}}\right)
\end{array}\right]=
$$$$
\left[\begin{array}{cccc|c}
x_{1}^{1} & x_{2}^{1} & \mathrm{~L} & x_{N}^{1} & f\left(\boldsymbol{x}^{1}\right) \\
x_{1}^{2} & x_{2}^{2} & \mathrm{~L} & x_{N}^{2} & f\left(\boldsymbol{x}^{2}\right) \\
\mathrm{M} & \mathrm{M} & \mathrm{M} & \mathrm{M} & \mathrm{M} \\
x_{1}^{S_{H M}} & x_{2}^{S_{H M}} & \mathrm{~L} & x_{N}^{S_{H M}} & f\left(\boldsymbol{x}^{S_{H M}}\right)
\end{array}\right]
$$

Hence, we have equation (2):

$$
x_{i}^{\text {new }}=\left\{\begin{array}{l}
x_{i}^{j}, j \in\left\{1,2, \ldots, S_{H M}\right\}, \\
\text { if } \text { rand }<H M C R \\
\bar{x}_{i} \in X_{i}, \text { otherwise }
\end{array}\right.
$$

As for $x_{i}^{\text {new }}$ from harmony memory, we have equation (3):

$$
x_{i}^{\text {new }}= \begin{cases}x_{i}^{\text {new }}+\text { rand }^{*} B W, & \text { if rand }<P A R(\text { Continuous }) \\ (k+\lambda) * x_{i}^{\text {new }}, \lambda \in[-1,1], & \text { if rand }<P A R(\text { Discrete }) \\ x_{i}^{\text {new }}, & \text { otherwise }\end{cases}
$$
i.e.,

The worst harmony is replaced with the new harmony,

$$
\boldsymbol{x}^{\text {worst }}=\boldsymbol{x}^{\text {new }} \text {, if } f\left(\boldsymbol{x}^{\text {new }}\right)<f\left(\boldsymbol{x}^{\text {worst }}\right)
$$

According to the analysis and description of routing problem in express delivery, the constraints can be expressed as:

(1) Distribution route length does not exceed the maximum value, i.e.,

$$
\sum_{k=1}^{n} d(k-1, k)+d(n, 0) \leq M D
$$

(2) The mathematical model of route programming can be defined as

$$
L=\min \left(\sum_{k=1}^{n} d(k-1, k)+d(n, 0)\right)
$$

Based on the gradient descent method, node center and base width parameter are:

$$
\begin{gathered}
w_{j}(k)=w_{j}(k-1)+\eta\left(y(k)-y_{m}(k)\right) h_{j} \\
+\alpha\left(w_{j}(k-1)-w_{j}(k-2)\right) \\
\Delta b_{j}=\left(y(k)-y_{m}(k)\right) w_{j} h_{j}\left(\frac{\left\|X-C_{j}\right\|^{2}}{b_{j}^{3}}\right) \\
b_{j}(k)=b_{j}(k-1)+\eta \Delta b_{j} \\
+\alpha\left(b_{j}(k-1)-b_{j}(k-2)\right) \\
\Delta c_{j, i}=\left(y(k)-y_{m}(k)\right) w_{j} \frac{x_{j}-c_{j, i}}{b_{j}^{2}}
\end{gathered}
$$

$$
\begin{aligned}
& c_{i j}(k)=c_{i j}(k-1)+\eta \Delta c_{i j} \\
& +\alpha\left(c_{i j}(k-1)-c_{i j}(k-2)\right)
\end{aligned}
$$

The outline design, and draw out the system structure chart of the teaching assistant system. In the implement phase system, the application of flash the technology is introduced, the module introduces the implementation process of the interactive function.

By this means, Traditional color theories and cognitive color principles can be merged into color computing technology, and become the fundamental color language of $\mathrm{CAD}$ and $\mathrm{CG}$ art. It built affective models of color, respectively on harmony, preference, and composition issues. In the section of color harmony quantification and harmonious color scheme generation, a set of computing principles attaining harmony were built in the HSL color space, and the method of generating harmonious color scheme was tested.

\section{EXPERIMENT RESULT}

Five teachers have conducted a series of experiments for the whole semester. 300 students were randomly chosen to do eleven kinds of questionnaires, informal discussions and color design tests, involving their experiences or viewpoints on four sub-ecological environments (namely physical learning environment, resourceful learning environment, technological learning environment and emotional learning environment), their actual use of multimedia electronic reading in college Color design class, their perspective of teachers' role, students' role, and the positioning of computers in learning, and the present attitudes for college students' autonomous Color design learning under the environment of multimedia electronic reading. With all of these, college students' actual needs are handy and their opinions or suggestions are collected. The interactive teaching system for color design course is shown as the figure 2 .

This kind of analysis is to provide relevant empirical basis for building and optimizing the model of multimedia electronic reading room -based foreign language learners' ecological environment. Specific measurements are shown in Table 1. The optimized learning environment is an ecological system with balanced input and output of material flow, information flow, energy flow and emotion flow. The ecological balance of macro-ecology displays the balance between four sub-environments which are material learning environment, resourceful learning environment, technological learning environment and emotional learning environment under the background of multimedia electronic reading. Table 2 shows measurement variable values of factors mentioned in the above table 1 .

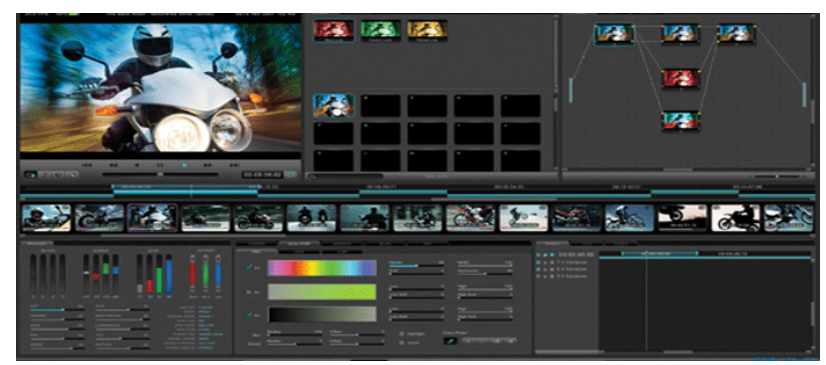

Figure 2. The teaching system for color design course 
SHORT PAPER

Design of INTERACTIVE TEACHING SYSTEM FOR COLOR DESIGN COURSE

TABLE I.

THE SPECIFIC MEASUREMENTS

\begin{tabular}{|c|c|c|c|}
\hline Dimension & Measurement & Dimension & Measurement \\
\hline \multirow{4}{*}{$\begin{array}{l}\text { Opportunistic } \\
\text { Behavior(OB) }\end{array}$} & Study against commitment (X1) & \multirow{8}{*}{$\begin{array}{l}\text { English quality } \\
\text { management } \\
(\mathrm{EQM})\end{array}$} & high-level participation (Y1) \\
\hline & Study against informal agreement for maximum benefit (X2) & & The quality of training (Y2) \\
\hline & Study drill a loophole in the contract to obtain interest (X3) & & Product design (Y3) \\
\hline & Study use accident forced our concessions (X4) & & Process management (Y4) \\
\hline \multirow{7}{*}{$\begin{array}{l}\text { Sharing behav- } \\
\text { ior (SB) }\end{array}$} & Study shared their production plan (X5) & & Quality data (Y5) \\
\hline & Study share their production capacity (X6) & & Benchmarking English (Y6) \\
\hline & Study share their production inventory (X7) & & Customer relationships (Y7) \\
\hline & We share production plan with Study (X8) & & Employee relations (Y8) \\
\hline & We Shared production capacity with Study (X9) & \multirow{7}{*}{$\begin{array}{l}\text { Study quality } \\
\text { management } \\
\text { (SQM) }\end{array}$} & Studv \\
\hline & We Shared production inventory with Study (X10) & & Study management (Y9) \\
\hline & We Shared our Study demand forecasting (X11) & & \\
\hline \multirow{4}{*}{$\begin{array}{l}\text { Cooperative } \\
\text { behavior }(\mathrm{CB})\end{array}$} & Study delivery processing speed (X12) & & choose (Y 10) \\
\hline & Study's delivery processing quality (X13) & & \multirow{3}{*}{ Study participation (Y11) } \\
\hline & Study of processing problem (X14) & & \\
\hline & Study' participation in product design level degree (X15) & & \\
\hline
\end{tabular}

TABLE II.

THe MEASurement VARiable VALUes of Factors

\begin{tabular}{|c|c|c|c|c|c|c|c|c|c|}
\hline \multirow{2}{*}{ Variable } & \multicolumn{2}{|c|}{ degrees of skewness } & \multicolumn{2}{|c|}{ degrees of kurtosis } & \multirow{2}{*}{ Variable } & \multicolumn{2}{|c|}{ degrees of skewness } & \multicolumn{2}{|c|}{ degrees of kurtosis } \\
\hline & Statistic standard & S.E & Statistic standard & S.E & & Statistic standard & S.E & Statistic standard & S.E \\
\hline $\mathrm{X} 1$ & 0.344 & 0.160 & 0.039 & 0.318 & Y1 & 0.595 & 0.160 & -0.224 & 0.318 \\
\hline $\mathrm{X} 2$ & 0.172 & 0.160 & -0.926 & 0.318 & Y2 & 0.400 & 0.160 & -0.098 & 0.318 \\
\hline $\mathrm{X} 3$ & 0.219 & 0.160 & -0.629 & 0.318 & $\mathrm{Y3}$ & 0.239 & 0.160 & 0.404 & 0.318 \\
\hline $\mathrm{X} 4$ & -0.148 & 0.160 & -1.318 & 0.318 & Y4 & 0.326 & 0.160 & 1.039 & 0.318 \\
\hline $\mathrm{X} 5$ & -0.100 & 0.160 & 0.222 & 0.318 & Y5 & 0.256 & 0.160 & -0.052 & 0.318 \\
\hline $\mathrm{X} 6$ & 0.316 & 0.160 & 0.105 & 0.318 & Y6 & 0.051 & 0.160 & 0.192 & 0.318 \\
\hline $\mathrm{X} 7$ & 0.201 & 0.160 & -0.213 & 0.318 & Y7 & -0.393 & 0.160 & 0.239 & 0.318 \\
\hline $\mathrm{X} 8$ & -0.087 & 0.160 & 0.189 & 0.318 & Y8 & 0.392 & 0.160 & -0.005 & 0.318 \\
\hline $\mathrm{X} 9$ & -0.033 & 0.160 & -0.254 & 0.318 & Y9 & 0.433 & 0.160 & 0.331 & 0.318 \\
\hline $\mathrm{X} 10$ & -0.029 & 0.160 & -0.175 & 0.318 & Y10 & 0.478 & 0.160 & 0.062 & 0.318 \\
\hline X11 & -0.083 & 0.160 & -0.292 & 0.318 & Y11 & -0.143 & 0.160 & 0.775 & 0.318 \\
\hline $\mathrm{X} 12$ & 0.481 & 0.160 & -0.453 & 0.318 & & & & & \\
\hline $\mathrm{X} 13$ & 0.471 & 0.160 & -0.503 & 0.318 & & & & & \\
\hline X14 & 0.452 & 0.160 & -0.073 & 0.318 & & & & & \\
\hline X15 & -0.205 & 0.160 & 0.650 & 0.318 & & & & & \\
\hline
\end{tabular}

\section{CONCLUSION}

This paper first teaching present situation of vocational school color design course and analyze problems, expounds the significance of color design teaching assistant system development background and development. According to the management information system demand analysis research method has carried on the demand analysis, function characteristics combined with the development of software for planning the teaching assistant system to achieve the function of. The outline design, and draw out the system structure chart of the teaching assistant system. In the implement phase system, the application of flash the technology is introduced, the module introduces the implementation process of the interactive function. Technical aspects of the main features of FLASHCS are introduced methods and principles of interaction design, the method call external files in FLASH. Color harmony can be gotten through hue, brightness, Chroma, tone and color solid. Single attribute color har- mony includes hue harmony, brightness harmony and Chroma harmony. In order to improve the performance of design of interactive teaching system for color design course, the author proposed a color collocation method. Double attributes harmony was realized by color tone design through synthesizing brightness with Chroma. Three attributes harmony was carried out by color harmony design in even color space with harmony framework. Research on color emotion, driven by color emotion, color emotional language was studied and classified, color emotion indices was set up, and the stylized color language was founded. Different colors will arouse people different emotions. In the web design, only to emphasize the application of color elements can we make our design more attractive. And the personality and aesthetic awareness about the web design can be vividly demonstrated. According to the principle and method of the color language coordinate, the three-dimensional semantic space of color scheme was established. 


\section{SHORT PAPER}

\section{DESIGN OF INTERACTIVE TEACHING SYSTEM FOR COLOR DESIGN COURSE}

\section{REFERENCES}

[1] H. Jing, "The Study on the Impact of Data Storage from Accounting Information Processing Procedure," International Journal of Database Theory and Application, vol. 8, no.3, pp. 323-332, June 2015. https://doi.org/10.14257/ijdta.2015.8.3.28

[2] X. Wang, J. W. Wang, Y. F. Zhong, et al., "Research of data mining technology application in personalized distance education platform," Journal of Heilongjiang Institute of Technology, 2010.

[3] C. Ji, M. Fan, "The application of web data mining in personalized modern distance education," Energy Procedia, vol.13, pp.714-720, 2011.

[4] Y. Li, J. Sun, and W. Qiang, "Application of Data Mining in Personalized Remote Distance Education Web System," Open Cybernetics \& Systemics Journal, vol. 9, no.1, pp.1769-1775, 2015. https://doi.org/10.2174/1874110X01509011769

[5] Li P. "Based on Data Mining Technology in Distance Education System Applied Research". Applied Mechanics \& Materials,
2014, 496-500:2260-2264. https://doi.org/10.4028/www.scientific. net/AMM.496-500.2260

[6] Santi Caballe, and Nicola Capuano, "Fifth International Workshop on Adaptive Learning via Interactive, Collaborative and Emotional Approaches (ALICE 2015)," International Journal of Emerging Technologies in Learning, vol. 11, no.7, pp. 4-5, July 2016. https://doi.org/10.3991/ijet.v11i07.6054

[7] Y. Gandole, "Computer Modeling and Simulation of Ultrasonic System for Material Characterization," Modeling and Numerical Simulation of Material Science, vol. 1, No.1, pp. 1-13, 2011. https://doi.org/10.4236/mnsms.2011.11001

\section{AUTHOR}

Fang Li is with ZhouKou Normal University Academy of Fine Arts, Henan, China (871178606@qq.com).

Submitted 09 September 2016. Published as resubmitted by the author 22 October 2016. 